\title{
DOUBLE-BLIND RANDOMIZED CLINICAL TRIAL OF KAEMPFERIA GALANGA L EXTRACT AS AN ANTI-INFLAMMATION (PROSTAGLANDIN E2 AND TUMOR NECROSIS FACTOR ALPHA) ON OSTEOARTHRITIS
}

\author{
NURPUDJI A TASLIM ${ }^{1 *}$, M NATSIR DJIDE ${ }^{2}$, YUSNITA RIFAI ${ }^{3}$, AKMAL NOVRIAN SYAHRUDDIN ${ }^{4}$, \\ YOSEFA RIA RAMPO ${ }^{1}$, MURNI MUSTAMIN ${ }^{1}$, SIGIT ANGRIAWAN ${ }^{4}$
}

\begin{abstract}
${ }^{1}$ Department of Nutrition, School of Medicine University of Hasanuddin, Makassar, Indonesia. ${ }^{2}$ Pharmaceutical Technology Laboratory, Faculty of Pharmacy University of Hasanuddin, Makassar, Indonesia. ${ }^{3}$ Pharmaceutical Chemistry Laboratory, Faculty of Pharmacy University of Hasanuddin, Makassar, Indonesia. ${ }^{4}$ Center for Food, Nutrition and Health Research, University of Hasanuddin,
\end{abstract} Jl. P. Kemerdekaan 90245, Makassar, Indonesia. Email: pudji_taslim@yahoo.com

Received: 26 January 2018, Revised and Accepted: 15 March 2019

\section{ABSTRACT}

Objective: The purpose of this study was to compare the effectiveness of the rhizome extract against inflammatory markers such as tumor necrosis factor (TNF)-alpha and prostaglandin E2 (PGE2) with meloxicam in patients with osteoarthritis at knee.

Materials and Methods: This study designed two phases as follows: The preparation of rhizome extract in a capsule dosage form which was then followed by double-blind clinical trials, randomized controlled, pre- and post-test design (18 cases) using the WOMAC scores for pain, to markers of inflammation using an enzyme-linked immunosorbent assay method.

Results: The results did not reveal any significant differences in pain scores, stiffnesses, and physical function impairment between the intervention (the rhizome extract) and control groups (meloxicam), it either did not reveal any significant differences in the parameters of inflammatory marker TNF alpha and PGE2 among the groups.

Conclusion: The rhizome extract had the same effect on pain, stiffness, physical interference as meloxicam, and on PGE2 as well as on the inflammatory marker TNF-alpha. Therefore, this extract can be used as an alternative herbal medicine for osteoarthritis.

Keywords: Osteoarthritis, Kaempferia galanga extract, Meloxicam, Tumor necrosis factor alpha, Prostaglandin E2.

(C) 2019 The Authors. Published by Innovare Academic Sciences Pvt Ltd. This is an open access article under the CC BY license (http://creativecommons. org/licenses/by/4. 0/) DOI: http://dx.doi.org/10.22159/ajpcr.2019.v12i5.31777

\section{INTRODUCTION}

Osteoarthritis is a progressive disease characterized by the degeneration of cartilage and joint tissue changes that cause pain, stiffness, and disability [1]. The disease is common in the elderly causing disability in old ages $[2,3]$. The incidence of osteoarthritis increases with age and is estimated about $80 \%$ of the population aged 65 years proven radiologically. A report released by the Indonesian Ministry Health in 2013 stated that the national prevalence in Indonesia reached 24.7\%. Specifically, for several regions in Indonesia reported high prevalence, in Pontianak $(89.91 \%$ cases) and the highest is at age $55-60$ years (28.93\%). The high prevalence of osteoarthritis disease requires serious attention to prevention, especially on the level of disability at old ages [1].

Management of osteoarthritis treatment is aimed at controlling pain and pain and improves function and quality of life. The use of nonsteroidal anti-inflammatory drug (NSAID) is effective in treating chronic pain in the knee. Meloxicam which is classified as NSAID has an analgesic function, anti-inflammatory, and antipyretic. However, long-term use has an impact on the side effects, particularly on the gastrointestinal system, including dyspepsia, gastric mucosal irritation, and bleeding [2]. The utilization of medicinal plants for the treatment of hereditary has been used and provided good results. Utilization empirically Kaempferia galanga by society as a drug is effective for nausea, cough, anti-inflammatory, colds, and sore [4-6]. This benefit is reinforced that the powder contains essential oils can provide analgesic and anti-inflammatory effects, especially in arthritis, The main chemical constituents of the essential oil is a compound of Ethyl p-methoxycinnamate $[7,8]$.
This study indicates that $K$. galanga rhizome extract can be an alternative for traditional medicine in relieving symptoms and clinical signs of inflammation on osteoarthritis such as pain, swelling, stiffness, and disability in addition to the provision of chemical drugs such as meloxicam.

\section{MATERIALS AND METHODS}

The study design includes two stages: The first stage of the preparation and manufacture of rhizome extract in a capsule dosage form which was then followed by double-blind randomized controlled clinical trials.

\section{Population and sample}

There are 35 people respondents in this study. Respondents are people with osteoarthritis of the knee in sub-district Puskesmas Tamalanrea Biringkanaya Makassar Indonesia. The diagnosis of osteoarthritis is based on the criteria of the American College of Rheumatology 2016. A radiological examination performed by a physician radiologist.

\section{RESULTS AND DISCUSSION}

\section{Result}

Table 1 shows the characteristics of respondents by gender as the highest percentage of women with $94.3 \%$ of respondents aged under 60 years $(60.0 \%)$. The education level of respondents was mostly in the category of compulsory education to 12 years $(94.3 \%)$ whereas $88.6 \%$ of respondents did not work. The mean body mass index (BMI) of respondents fall into the category of obesity and all parameters of blood tests are normal except in the category of prostaglandin E2 (PGE2) and tumor necrosis factor (TNF)-alpha. These values are above normal. 
Table 2 shows the average examination results of both the intervention and control groups. The mean BMI in both groups shows above normal values which enter the category of obesity. Meanwhile, blood examination results of both groups show normal values except for the levels of PGE2 and TNF-alpha value. Inspection parameters in the two groups have equal value because they did not differ significantly ( $p>0.05)$ in all parameters. This indicates that the data at the time of the initial baseline between the intervention and control groups are normally distributed and homogeneous.

Table 3 shows the increase in ureum levels within the two groups. The control group exhibits a significant increase $(<0.05)$ whereas the increase in the intervention group was not significant $(\mathrm{p}>0.05)$. Nonetheless, value ureum levels for both groups fall into the category of normal. Serum glutamate oxaloacetate transaminase (SGOT) in the control group decreased significantly $(\mathrm{p}<0.05)$, whereas the intervention group experienced an increase but not significant $(\mathrm{p}>0.05)$. The value of SGOT levels for both groups falls into the category of normal.

The PGE2 biomarker value for the intervention group decreased prior and after the administration of rhizome extract but this impairment is not significant $(p>0.05)$. In contrast, the control group experienced a rise although not significant $(p>0.05)$. The main values in the two groups, however, were not different $(p>0.05)$.

The TNF-alpha biomarker value for the intervention group increased significantly $(\mathrm{P}<0.05)$ but not for the control group. However, when compared to the difference in the mean values before and after the two groups, the results were not different $(p>0.05)$.

\section{Discussion}

\section{Population research overview}

Weight loss is a risk factor for the incidence of osteoarthritis of the knee [9]. The greater the person's weight, the more at risk for knee osteoarthritis [10]. The results, in this study, showed that the majority of the study sample radiographically classified as obese. This data indicate that the status of obesity affects the severity of osteoarthritis. There are two samples with a BMI $>25$ were considered obese (obese II). Both of these samples dropped out of the study when the intervention took place on the grounds in which the administered dose was not able to reduce the pain. This happens because the drug dose does not take into account the intervention given sample weight so that the possibility of inadequate doses given.

Table 1: Characteristics and examination results mean respondents $(n=35)$

\begin{tabular}{|c|c|c|}
\hline Parameters & $\% / \mathrm{X} \pm \mathrm{XD}$ & Normal values \\
\hline \multicolumn{3}{|l|}{ Gender } \\
\hline Man & 5.7 & \\
\hline Woman & 94.3 & \\
\hline \multicolumn{3}{|l|}{ Age (year) } \\
\hline$<60$ & 60.0 & \\
\hline$\geq 60$ & 40.0 & \\
\hline \multicolumn{3}{|l|}{ Level of education } \\
\hline \multicolumn{3}{|l|}{ Work } \\
\hline Work & 88.6 & - \\
\hline Does not work & 11.4 & \\
\hline Age & $58.34 \pm 8.69$ & - \\
\hline TB & $148.91 \pm 6363$ & - \\
\hline BB & $57.94 \pm 10.29$ & - \\
\hline IMT & $26.04 \pm 3.61$ & $18.5-23 \mathrm{~kg} / \mathrm{m}^{2}$ \\
\hline $\mathrm{hb}$ & $12.93 \pm 0.95$ & $\mathrm{p}=(12.0-14.0 \mathrm{~g} / \mathrm{dl}), \mathrm{L}=(14.0-16.0 \mathrm{~g} / \mathrm{dl})$ \\
\hline creatinine & $0.62 \pm 0: 12$ & $0.6-1.2 \mathrm{mg} / \mathrm{dl}$ \\
\hline Uric acid & $5: 38 \pm 1: 49$ & $2.4-6.0 \mathrm{mg} / \mathrm{dl}$ \\
\hline SGOT & $22.94 \pm 7: 14$ & $<31 \mathrm{U} / \mathrm{L}$ \\
\hline SGPT & $20.66 \pm 9.68$ & $<32 \mathrm{U} / \mathrm{L}$ \\
\hline PGE2 & $746.95 \pm 627.91$ & $200-400 \mathrm{pg} / \mathrm{ml}$ \\
\hline TNF-alpha & $1371.51 \pm 1587.66$ & $0-100 \mathrm{pg} / \mathrm{ml}$ \\
\hline
\end{tabular}

TB: Total bilirubin, BB: Bilirubin, IMT: Intima-media thickness, SGOT: Serum glutamate oxaloacetate transaminase, SGPT: Serum glutamate pyruvate transaminase, PGE2: Prostaglandin E2, TNF: Tumor necrosis factor

Table 2: Average of examination respondents in intervention group $(n=18)$ and controls $(n=17)$

\begin{tabular}{lllll}
\hline Parameters & Intervention group (X \pm XD) & Control group $(X \pm X D)$ & p value & Normal values \\
\hline Age & $57.78 \pm 8.63$ & $58.94 \pm 8.98$ & $0699^{*}$ & - \\
TB & $149.11 \pm 6: 09$ & $148.71 \pm 6.83$ & $0854^{*}$ & - \\
BB & $59.67 \pm 10: 02$ & $56.11 \pm 10: 55$ & $0314^{*}$ & - \\
IMT & $26.80 \pm 3.82$ & $25.24 \pm 3: 30$ & $0207^{*}$ & $18.5-23 \mathrm{~kg} / \mathrm{m}^{2}$ \\
hb & $12.81 \pm 1: 07$ & $13: 06 \pm 0.83$ & $0441^{*}$ & $\mathrm{p}=(12.0-14.0 \mathrm{~g} / \mathrm{dl}), \mathrm{L}=(14.0-16.0 \mathrm{~g} / \mathrm{dl})$ \\
ureum & $27.56 \pm 8: 21$ & $23: 06 \pm 6: 08$ & $0155^{* *}$ & $10-50 \mathrm{mg} / \mathrm{dl}$ \\
creatinine & $0.62 \pm 0: 12$ & $0.61 \pm 0: 12$ & $0704^{* *}$ & $0.6-1.2 \mathrm{mg} / \mathrm{dl}$ \\
Uric acid & $5: 51 \pm 1: 20$ & $5: 25 \pm 1.77$ & $0150^{* *}$ & $2.4-6.0 \mathrm{mg} / \mathrm{dl}$ \\
SGOT & $22: 00 \pm 6.70$ & $23.94 \pm 7.64$ & $0290^{* *}$ & $<31 \mathrm{U} / \mathrm{L}$ \\
SGPT & $19.89 \pm 5.75$ & $21: 47 \pm 12.74$ & $0631^{* *}$ & $<32 \mathrm{U} / \mathrm{L}$ \\
PGE2 & $688.90 \pm 671.25$ & $808.41 \pm 592.70$ & $0509^{* *}$ & $200-400 \mathrm{pg} / \mathrm{ml}$ \\
TNF-alpha & $1245.20 \pm 1526.86$ & $1505.26 \pm 1685.96$ & $0692^{* *}$ & $10-100 \mathrm{pg} / \mathrm{ml}$ \\
\hline
\end{tabular}

*Independent t-test; **Mann-Whitney, TNF: Tumor necrosis factor, PGE2: Prostaglandin E2, TB: Total bilirubin, BB: Bilirubin, IMT: Intima-media thickness,

SGOT: Serum glutamate oxaloacetate transaminase, SGPT: Serum glutamate pyruvate transaminase 
Table 3: Respondents comparative analysis laboratory research before and after treatment

\begin{tabular}{|c|c|c|c|c|}
\hline Parameters & Pre-test $(\mathrm{X} \pm \mathrm{XD})$ & Post-test $(\mathrm{X} \pm \mathrm{XD})$ & Difference $(X \pm X D)$ & $p$ value \\
\hline \multicolumn{5}{|l|}{$\mathrm{Hb}$} \\
\hline Intervention & $12.81 \pm 1: 07$ & $12.71 \pm 0.85$ & $-0.11 \pm 0.68$ & $0477^{* * * *}$ \\
\hline Control & $13: 06 \pm 0.83$ & $12.83 \pm 0.78$ & $-0.24 \pm 0.65$ & $0158 * * *$ \\
\hline $\mathrm{p}$ value & $0441^{*}$ & $0597^{* *}$ & $0571^{*}$ & \\
\hline \multicolumn{5}{|l|}{ Ureum } \\
\hline Intervention & $27.56 \pm 8: 21$ & $28.39 \pm 7: 05$ & $0.83 \pm 7: 37$ & $0637^{* * *}$ \\
\hline Control & $23: 06 \pm 6: 08$ & $27.12 \pm 7: 46$ & $4: 06 \pm 7: 32$ & $0051^{* * * *}$ \\
\hline \multicolumn{5}{|l|}{ Creatinine } \\
\hline Intervention & $0.62 \pm 0: 12$ & $0.61 \pm 0: 11$ & $-0.01 \pm 0: 08$ & $0508 * * *$ \\
\hline Control & $0.61 \pm 0: 12$ & $0.66 \pm 0: 23$ & $0: 04 \pm 0: 14$ & $0477^{* * * *}$ \\
\hline $\mathrm{p}$ value & $0704^{* *}$ & $0934^{* *}$ & $0221^{* *}$ & \\
\hline \multicolumn{5}{|l|}{ Uric acid } \\
\hline Intervention & $5: 51 \pm 1: 20$ & $5.66 \pm 1: 23$ & $0: 16 \pm 1: 22$ & $0594 * * *$ \\
\hline Control & $5: 25 \pm 1.77$ & $5: 53 \pm 2: 09$ & $0: 28 \pm 0.73$ & $0285^{* * * *}$ \\
\hline $\mathrm{p}$ value & $0150^{* *}$ & $0276^{* *}$ & $0817^{* *}$ & \\
\hline Intervention & $22: 00 \pm 6.70$ & $22.61 \pm 9.72$ & $0.61 \pm 6: 20$ & $0727^{* * * *}$ \\
\hline Control & $23.94 \pm 7.64$ & $19.76 \pm 3: 56$ & $-4.18 \pm 6: 39$ & $0004^{* * * *}$ \\
\hline $\mathrm{p}$ value & $0290 * *$ & $0702^{* *}$ & $0084^{* *}$ & \\
\hline \multicolumn{5}{|l|}{ SGPT } \\
\hline Intervention & $19.89 \pm 5.75$ & $22: 33 \pm 9: 50$ & $2: 44 \pm 8.80$ & $0468^{* * * *}$ \\
\hline Control & $21: 47 \pm 12.74$ & $18: 53 \pm 6.95$ & $-2.94 \pm 9: 58$ & $0132^{* * * *}$ \\
\hline $\mathrm{p}$ value & $0631^{* *}$ & $0149 * *$ & $0202^{* *}$ & \\
\hline \multicolumn{5}{|l|}{ PGE2 } \\
\hline Intervention & $688.90 \pm 671.25$ & $668.73 \pm 586.39$ & $-20.17 \pm 360.36$ & $0472 * * * *$ \\
\hline Control & $808.41 \pm 592.70$ & $854.90 \pm 612.36$ & $546.27 \pm 46.49$ & $0407^{* * * *}$ \\
\hline $\mathrm{p}$ value & $0509^{* *}$ & $0204^{* *}$ & $0644^{* *}$ & \\
\hline \multicolumn{5}{|l|}{ TNF-alpha } \\
\hline Intervention & $1245.20 \pm 1526.86$ & $1500.88 \pm 1742.15$ & $255.69 \pm 1087.68$ & $0018 * * * *$ \\
\hline Control & $1505.26 \pm 1685.96$ & $1847.82 \pm 1631.42$ & $342.56 \pm 1149.57$ & $0227^{* * * *}$ \\
\hline $\mathrm{p}$ value & $0692^{* *}$ & $0409 * *$ & $0509 * *$ & \\
\hline
\end{tabular}

*Independent t-test, **Mann-Whitney, ${ }^{* * *}$ Paired t-test, ${ }^{* * * * W}$ Wlcoxon, TNF: Tumor necrosis factor, SGOT: Serum glutamate oxaloacetate transaminase, SGPT: Serum glutamate pyruvate transaminase, PGE2: Prostaglandin E2

\section{K. galanga extract effect against PGE2}

PGE2 is an important mediator of the inflammatory process and is produced at sites of inflammation by Cyclooxygenase-2 (COX-2) [10]. This study showed decreased levels of PGE2 after intervention by $K$ galanga rhizome extract, but this decrease was not statistically significant. The rhizome extract administered in mice in two doses; $600 \mathrm{mg} / \mathrm{kg}$ and $1200 \mathrm{mg} / \mathrm{kg}$, respectively. Doses significantly give antiinflammatory and anti-analgesic activities, respectively, compared to mice treated with aspirin $(100 \mathrm{mg})$ and codeine $(5 \mathrm{mg})$. The rhizome extract was given only in the dose of $160 \mathrm{mg}$. Results were not achieved in this study likely due to the very low given doses. There are several studies on the effects of rhizome extract against inflammatory and analgesic on mice and the obtained results essentially significantly reduced inflammatory and analgesic effects.

PGs play a key role in the pain experience of injury, inflammation, malignancies, and many other conditions [10]. PGs have a central role in the pathophysiology of arthritis and pain. Chondrocytes isolated from patients with osteoarthritis generate 50-fold more PGE2 than chondrocytes from patients without osteoarthritis. PG stimulates the release of matrix metalloproteinase (MMP), which can contribute to joint disorders. PGs can also have an effect on the osteoclast/osteolysis. COX-2 transcription settings for inflammatory arthritis is influenced by

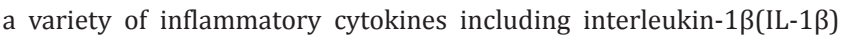
and TNF $\alpha$. Meloxicam and COX-2 selective inhibitors prevent PGE2 production in response to IL-1 and TNF $\alpha$ in rheumatoid synovium. IL-1 $\beta$ may stimulate pathways inducible nitric oxide (NO), thus increasing the NO. NO can act as secondary intermediaries that mediate sensitization nociceptors in sensory neurons, induces the production of PG through upregulation of COX-2. When MMP is activated, it causes cartilage degradation and chondrocyte apoptosis triggered. NOtriggered chondrocyte apoptosis is facilitated by the specific inhibition of PGE2 and COX-2 [10].

\section{CONCLUSION}

There were no significant differences in the parameters of inflammatory markers that TNF-alpha and PGE2 between the intervention (K. galangal rhizome extract) and control groups (meloxicam); the rhizome extract has the same effect on pain, stiffness, physical interference with meloxicam, and the PGE2 and the inflammatory marker TNF-alpha. Therefore, the similar effect of $K$. galanga rhizome extract to the effect with the meloxicam can be used as a replacement for osteoarthritis drugs.

\section{CONFLICTS OF INTEREST}

All authors have none to declare.

\section{REFERENCES}

1. Fransen M, Bridgett L, March L, Hoy D, Penserga E, Brooks P, et al. The epidemiology of osteoarthritis in Asia. Best Clin Pract Res 2011;14:113-21.

2. Dwicandra N, Setiadi A. Comparison of pain score in osteoarthritis patients treated with a combination of diacerein and meloxicam and meloxicam alone. Int Pharm Pharm Sci 2017;9:69-73.

3. Sulthana N, Vijaya K. Prevention of peptic ulcers by curcumin in chemically induced ostheoarthritis. Int Pharm Pharm Sci 2018;10:29-34.

4. Kanjanapothi D, Panthong A, Lertprasertsuke N, Taesotikul T, Rujjanawate C, Kaewpinit D, et al. Toxicity of crude rhizome extract of Kaempferia galanga L. (Proh hom). J Ethnopharmacol 2004; $90: 359-65$

5. Karsdal MA, Michaelis M, Ladel C, Siebuhr AS, Bihlet AR, Andersen JR, et al. Disease-modifying treatments for osteoarthritis (DMOADs) of the knee and hip: Lessons learned from failures and opportunities for the future. Osteoarthritis Cartilage 2016;24:2013-21.

6. Martel-Pelletier J, Pelletier JP. Is osteoarthritis a disease involving only cartilage or other articular tissues? Eklem Hastalik Cerrahisi 2010;21:-14 
7. Mohanty S, Parida R, Singh S, Joshi RK, Subudhi E, Nayak S. Biochemical and molecular profiling of micropropagated and conventionally grown Kaempferia galanga. Plant Cell Tissue Organ Cult 2011;106:39-46.

8. Ridtitid W, Sae-Wong C, Reanmongkol W, Wongnawa M. Antinociceptive activity of the methanolic extract of Kaempferia galanga Linn. In experimental animals. J Ethnopharmacol 2008;118:225-30.
9. Smith HS, Baird W. Pharmaceutical update Meloxicam and selective COX-2 inhibitors in the management of pain in the palliative care population. Am J Hosp Palliat Care 2016;20:297-306.

10. Turajane $\mathrm{T}$, Wongbunnak $\mathrm{R}$, Patcharatrakul $\mathrm{T}$, Ratansumawong $\mathrm{K}$, Poigampetch Y, Songpatanasilp T, et al. Gastrointestinal and cardiovascular risk of non-selective NSAIDs and COX-2 inhibitors in elderly patients with knee osteoarthritis. J Med Assoc Thai 2009;92 Suppl 6:S19-26. 